\title{
A core outcome set development for a French national prospective study about the effect of mediolateral episiotomy on obstetric anal sphincter injury during operative vaginal delivery (INSTRUMODA)
}

Bertrand Gachon ${ }^{1,2,3^{*}}$ D. Thomas Schmitz ${ }^{4}$, France Artzner ${ }^{5}$, Olivier Parant ${ }^{6}$, Renaud De Tayrac ${ }^{7}$, Guillaume Ducarme ${ }^{8}$, Camille Le Ray ${ }^{9}$, Anne Cécile Pizzoferrato ${ }^{10}$, Charles Garabedian ${ }^{11}$, Didier Riethmuller ${ }^{12}$, Fabrice Pierre ${ }^{1}$, Stephanie Ragot ${ }^{2}$, Xavier Fritel ${ }^{1,2}$ and the GROG (Groupe de Recherche en Gynécologie Obstétrique)

\begin{abstract}
Background: We aimed at developing a core outcome and variables of interest set to investigate the effects of mediolateral episiotomy on Obstetric Anal Sphincter Injury (OASI) during and after operative delivery in nulliparous women in a large-scale one-year observational French study including 15,000 women (INSTRUMODA).

Methods: A list of outcomes and variables of interest was suggested to obstetricians participating in the INST RUMODA study using online questionnaires divided into 7 categories: the woman's history and course of pregnancy, course of labor, modalities of operative delivery, episiotomy characteristics, immediate maternal morbidity, one-year maternal morbidity, immediate neonatal morbidity. We used a three-round DELPHI method to reach a consensus. In the first round, outcomes and variables considered as essential by $70 \%$ or more of obstetricians were included in the corpus whereas they were excluded when $70 \%$ rated them as "not important". In the second round, non-consensual outcomes and variables were reassessed and excluded or definitively included if considered as "not important" or essential by $50 \%$ or more of the obstetricians. During the first round, obstetricians were invited to suggest new outcomes and/or variables that were then assessed in the second and third round. We used the same method to develop a core outcome and variables of interest set in a population of women in the community recruited via an association of patients. At the end of the procedure the core outcome and variables of interest sets were merged to provide the final core outcome set for the INSTRUMODA study.

\footnotetext{
* Correspondence: bertrand.gachon@gmail.com

'Poitiers University Hospital, Department of Obstetrics and Gynecology,

Poitiers, France

${ }^{2}$ INSERM CIC-P 1402, Poitiers University Hospital, Poitiers, France

Full list of author information is available at the end of the article
}

(c) The Author(s). 2021 Open Access This article is licensed under a Creative Commons Attribution 4.0 International License, which permits use, sharing, adaptation, distribution and reproduction in any medium or format, as long as you give appropriate credit to the original author(s) and the source, provide a link to the Creative Commons licence, and indicate if changes were made. The images or other third party material in this article are included in the article's Creative Commons licence, unless indicated otherwise in a credit line to the material. If material is not included in the article's Creative Commons licence and your intended use is not permitted by statutory regulation or exceeds the permitted use, you will need to obtain permission directly from the copyright holder. To view a copy of this licence, visit http://creativecommons.org/licenses/by/4.0/. The Creative Commons Public Domain Dedication waiver (http://creativecommons.org/publicdomain/zero/1.0/) applies to the data made available in this article, unless otherwise stated in a credit line to the data. 
(Continued from previous page)

Results: Fifty-three obstetricians and 16 women filled out questionnaires. After the 3 rounds of Delphi procedure in each population, 74 outcomes and variables were consensually reported by obstetricians and 92 by women in the community. By mixing these two consensual corpora we reported a final consensual list of 114 variables of interest and outcomes for both obstetricians and women.

Conclusion: We established a core outcome and variables of interest set among obstetricians and women in the community to investigate the association between mediolateral episiotomy and OASI during operative delivery.

Trial registration: The INSTRUMODA study was registered on https://clinicaltrials.gov on June 25, 2020 (NCT04446 780).

Keywords: Obstetric anal sphincter injury, Operative delivery, Episiotomy, Core outcome set

\section{Background}

Obstetric anal sphincter injury (OASI) is a maternal delivery complication defined as a perineal tear involving at least a superficial tear of the external anal sphincter and, at worst, an opening of the rectal mucosae [1, 2]. Such a perineal trauma is associated with significant alteration in women's health: anal incontinence, perineal pain, dyspareunia, and postnatal depression [3]. There have been several risk factors reported for OASI occurrence, among which the most important are nulliparity and operative vaginal delivery, especially in case of forceps delivery [1-4]. When these two risk factors are associated, OASI prevalence ranging from 2 to $20 \%$ has been reported [5-8]. Even when such a high-risk situation is clearly identified, preventive strategies to avoid OASI occurrence remains disappointing.

As regards spontaneous vaginal delivery, an abundant literature reports that routine mediolateral episiotomy does not protect against OASI [9]. As regards its interest in operative vaginal delivery, the existing data are subject to considerable debate. While several retrospective studies have reported that mediolateral episiotomy has a protective effect against OASI, a small pilot randomized trial failed to identify a significant preventive effect $[5-8,10,11]$. This lack of definitive evidence means that the protective effect of mediolateral episiotomy in operative delivery remains hypothetical. Because OASI is a low frequency event and because episiotomy has its own morbidity (pain, dyspareunia, infection), systematic episiotomy may induce more harm than good [9]. There are consequently no clear recommendations about its use during operative vaginal delivery $[2,12,13]$.

We have chosen to conduct a large-scale French observational study, for 1 year in more than 120 recruiting centers, with 15,000 expected inclusions of nulliparous women who will undergo operative vaginal delivery with or without mediolateral episiotomy (INSTRUMODA, NCT 04446780 https://clinicaltrials.gov). In cases of operative delivery, we will assess, the effect of mediolateral episiotomy (versus no) on OASI occurrence in cases of instrumental delivery, on immediate and one-year maternal morbidity, and on neonatal immediate morbidity. Propensity scores will be used to control for indication bias. The study is expected to start by the first trimester of 2021.

We have aimed at organizing a study that fits with both women and obstetrician's expectations. Such an objective implies that initially, we interrogate women and professional on their expectations in view of consensually defining a corpus of endpoints. Indeed, an approach centered on both patient and professional consensual expectations is more and more often considered as a quality indicator for research projects and required by journals and funding organizations [14-16].

The main endpoint of this study was to develop a core outcome and variable of interest set on the endpoints to be addressed in the INSTRUMODA study.

\section{Methods}

This Core Outcome Set procedure was led prospectively using an online questionnaire. The procedure that we detail precisely below followed the COS-STAD recommendations for core outcome set developments and the COMET guidelines $[15,16]$.

\section{Constitution of a scientific committee}

We have organized a scientific committee to steer the INSTRUMODA study (see authors list). The 13 members of this committee are obstetricians with a specific interest in perineal trauma at childbirth, methodologist, or patient representatives (Collectif inter associative autour de la naissance). All the committee members were involved in the overall design of the INST RUMODA study, including core outcome set processing.

\section{Identification of outcomes and variables of interest}

Based on clinical or methodological experience, the scientific committee suggested a list of outcomes and variables of interest divided into 7 categories: woman's characteristics and course of pregnancy, course of labor, modalities of operative delivery, modality of episiotomy, 
immediate maternal morbidity, immediate neonatal morbidity and one-year maternal morbidity. For each category, a list of outcomes and variables was consensually formulated by the scientific committee.

We chose to dichotomize the list of suggested outcomes and variables of interest with one corpus for the obstetricians (Additional file 1) and a second corpus for women in the community (Additional file 2). Our choice was justified by our considering that the understanding and interpretation of the suggestions might differ between the two samples.

We initially elaborated the list of outcomes and variables and processed the core outcome and variable of interest set for obstetricians and secondly, did the same for women in the community. At the end of the processing, the two corpuses of consensual outcomes and variables of interest were mixed to provide a final corpus of outcomes.

\section{Constitution of stakeholder groups}

To constitute the obstetrician stakeholder group, we invited all the main investigators in all the planned recruiting centers of the INSTRUMODA study to participate in the Core outcome and variable of interest set processing. They were contacted by email and invited to participate in the consensus process. To constitute the stakeholder group composed of women in the community, we contacted volunteer women through a patient representative association (Collectif interassociatif autour de la naissance). Women were contacted by email and invited to participate in the consensus processing using online questionnaires in a same way as professionals. All these women had a personal birth experience, and they have a special interest about protecting mother's health and autonomy during childbirth.

For both women and professionals, it was clearly indicated that we expected them to consensually define a list of outcomes and variables of interest that could be investigated in the INSTRUMODA study.

\section{Consensus processing}

We defined a priori modalities of consensus processing that were comparable for both obstetricians and women. The process is based on a DELPHI method and with conformity with the COS-STAD recommendations for core outcome set developments and the COMET guidelines $[15,16]$.

In a first round of online questionnaires, participants were asked to attribute a level of importance to all the suggestions from the scientific committee, using a threelevel scale: not important, important but not essential, essential. When at least $70 \%$ of respondents considered the item as essential, it was included in the consensual corpus. Conversely, when at least $70 \%$ of respondents considered the item as not important, it was excluded from the process. All the outcomes and variables for which the consensus was not reached were included in a second round of online questionnaires. During the firstround volunteers were asked to suggest additional outcomes and/or variables of interest for a consensus processing assessment during the second round.

In the second round, volunteers were requested to definitively attribute a level of importance to nonconsensual outcomes and variables from the 1st round: important versus not important. It was clearly indicated that "important" meant that the item would be assessed in the INSTRUMODA study and that "not important" meant that it would not be assessed. When at least $50 \%$ of respondents considered the item as important, it was included in the consensual corpus; if there were less than $50 \%$, it was excluded. During the second round respondents were also asked to attribute a level of importance to a list of new outcomes and variables of interest suggested during the first round in the same way as previously reported: not important, important but not essential, essential. These new outcomes and variables were then either included in the consensual corpus, excluded from the corpus or included in a third round of questionnaires with exactly the same methods as those applied in the 1st round.

Last, in the third round of questionnaires, respondents were asked to definitively attribute a level of importance to outcomes and variables added in the first round and not consensual in the second round. We used exactly the same methods as those applied in reported for the second round, and outcomes and variables considered by $50 \%$ or more of respondents as important were included in the consensual corpus.

At the end of the process, having obtained a core outcome and variables of interest set from both obstetricians and women in the community, we mixed these 2 corpuses to provide a final core outcome set.

\section{Ethical and regulatory considerations}

This study involves only volunteers for anonymous online questionnaire answering, without any identifying information collection and with a total independence from any medical care. This considered, regarding the French legislation about medical research involving human person (Loi Jardé), an ethical committee approbation is not required (https://www.legifrance.gouv.fr/codes/id/ LEGISCTA000032722874/2017-06-14/).

The INSTRUMODA study was registered on https:// clinicaltrials.gov on June 25, 2020 (NCT 04446780). The INSTRUMODA project have been approved by an ethical committee: Comité de Protection des Personnes Nord Ouest IV (ID RCB: 2020-A01974-35). 


\section{Results}

Development of a core outcome and variable of interest set in the population of obstetricians

At the time of organization of the core outcome and variables of interest set process, we planned to recruit 109 centers and an invitation to participate was sent to the main investigator of each center. There was one male midwife working in a public hospital, and 108 obstetricians. Among the 108 obstetricians 64 were males (59.3\%) and 44 females (40.7\%), they worked in public hospital for 92.6\% (100 obstetricians) and 8 worked in a private maternity (7.4\%). Each was the local volunteer to coordinate the INSTRUMODA study in its maternity and can be the head of the department but without any obligation.

\section{First round}

Sixty-five outcomes and variables of interest were suggested by the scientific committee and assessed by the stakeholder group. Fifty-three volunteers filled out the online questionnaire (48.6\%). Thirty-one outcomes or variables were included in the final consensual corpus and none were excluded (Fig. 1). The stakeholder group suggested 18 new outcomes and variables: woman's geographic origin, vaginismus before delivery, anal incontinence during pregnancy, maternal fever during labor, oxytocin use, number of vaginal examinations, fetal heart analysis during expulsive phase, maneuver of active delivery of the anterior arm (Couder maneuver), instrument justification, antenatal discussion about episiotomy

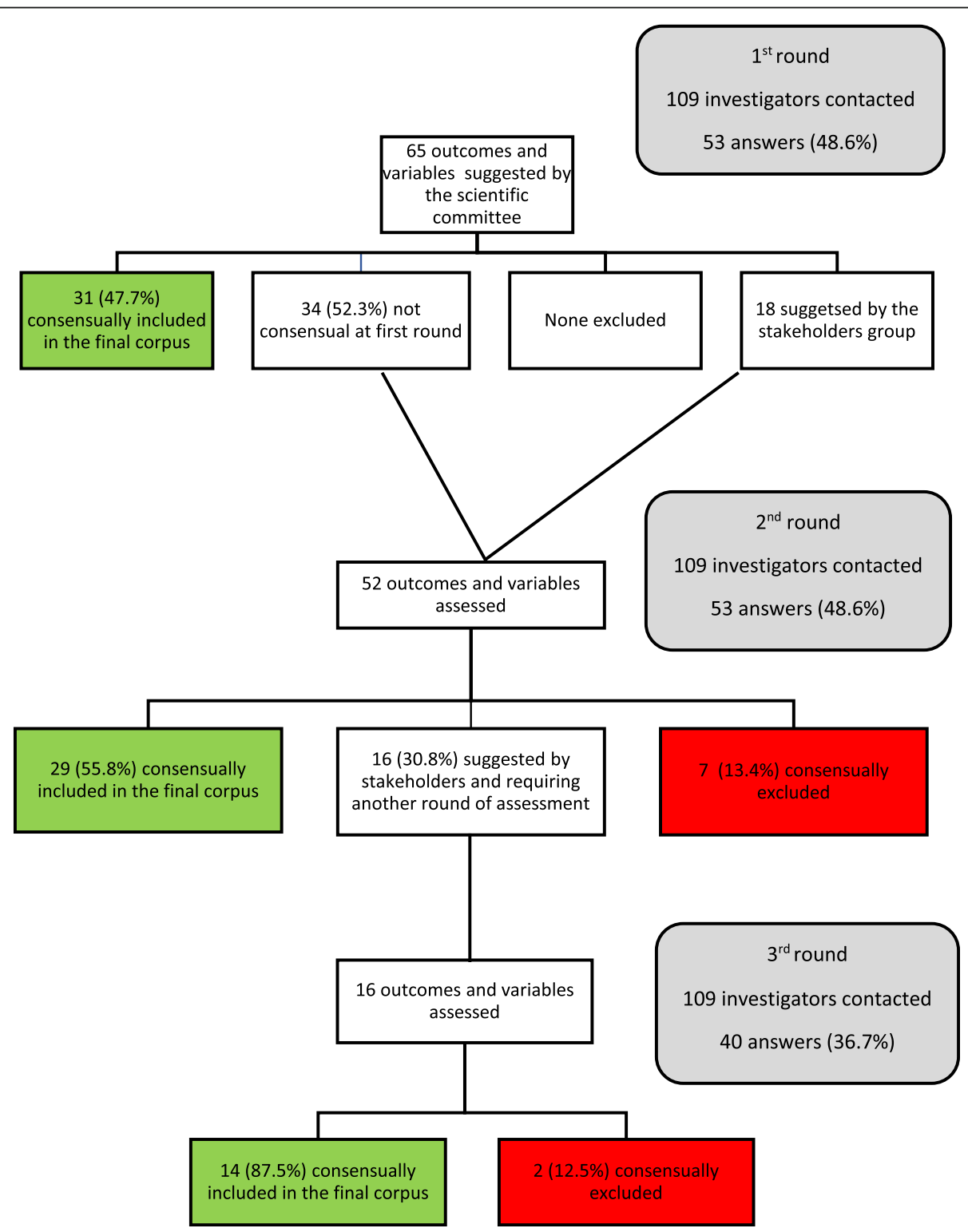

Fig. 1 Flow Chart for the consensus process in the group of professionals 
in a birth project, experience of the practitioner performing episiotomy, analgesia for episiotomy incision, postpartum urinary retention, neonatal analgesic consumption, bone fracture, Cephalhematoma and/or subgaleal hemorrhage, wish for another pregnancy, in case of another pregnancy wish for vaginal delivery.

\section{Second round}

The same 109 investigators were contacted and 53 filled out the online questionnaire. Fifty outcomes and variables were assessed: 34 suggested by the scientific committee and not consensual during $t$ the first round, 18 suggested by the stakeholder group. Twenty-nine outcomes and variables were definitively included in the corpus (Fig. 1). Seven were excluded: need for medical assistance for procreation, methods for labor induction, ultrasound assessment of fetal head station, antibioprophylaxis for operative delivery, angle of episiotomy suture from the midline, self-declared episiotomy length, length of episiotomy suture.

\section{Third round}

Forty of the 109 contacted investigators filled out the online questionnaire (36.7\%). Sixteen outcomes and variables suggested by the stakeholder group required a final assessment. Fourteen were definitively included and 2 were excluded (number of vaginal examinations, antenatal discussion about episiotomy within a birth project) (Fig. 1).

\section{Development of a core outcome and variable of interest set in the population of women in the community}

Twenty-four women were contacted and requested to fill out the 1st round of online questionnaire.

\section{First round}

Sixteen of the 24 women contacted filled out the questionnaire (66.7\%). Out of the 82 outcomes and variables suggested by the scientific committee, 55 were consensually included in the final corpus and none were excluded (Fig. 2). The stakeholder group suggested 14 new outcomes and variables: personal history of depression, self-rated anxiety before delivery, self-rated physical fatigue before operative delivery, self-rated psychological fatigue before operative delivery, self-rated concern immediately before operative delivery, attempt at manual fetal rotation, change of maternal position during the expulsive phase before deciding on an operative delivery, analgesia for episiotomy incision, analgesia for episiotomy reparation, difficulty of movement after delivery, self-rated level of understanding about interventions for the delivery, postnatal vaginismus, wish to prepare a birth project in case of another pregnancy, neonate hospitalization in a unit different from that the mother.

\section{Second round}

The same 24 women were contacted and 16 filled out the online questionnaire (66.7\%). Forty-one outcomes and variables of interest were assessed: 27 for a second assessment and the 14 suggested by the stakeholder group. Thirty-one outcomes were consensually included in the final corpus and 4 were excluded: women's geographic origin, maternal smoking, medical assistance for procreation, hour of birth (Fig. 2).

\section{Third round}

The same 24 women were contacted and 15 filled out the online questionnaire (62.5\%). Six outcomes and variables suggested by the stakeholder group that were not consensual at the previous round were assessed and all were definitively included in the consensual corpus (Fig. 2).

\section{Constitution of the final core outcome and variable of interest set}

All in all, 74 outcomes were consensually considered as important by obstetricians and 92 by women in the community. After mixing them in a single corpus, there resulted a corpus of 114 consensual outcomes and variables of interest (Table 1).

\section{Discussion}

Main findings

We developed a core outcome and variable of interest set that will be used in the INSTRUMODA study to assess the effect of mediolateral episiotomy on OASI occurrence during operative vaginal delivery in nulliparous women. A list of 114 outcomes and variables divided into 7 categories was consensually included by obstetricians and women in the community: women's history and course of pregnancy, course of labor, modalities of operative delivery, episiotomy, immediate maternal morbidity, one-year maternal morbidity and immediate neonatal morbidity.

\section{Strengths and limitations}

The first strength of this study is that it is the first consensual statement of outcomes and variables of interest for a research protocol investigating OASI, episiotomy and morbidity associated with operative vaginal delivery. This first report offers a possibility of providing further study protocols on this theme as close as possible to the expectations of both women and professionals.

Second, our process is in accordance with both the COS-STAD recommendations for core outcome set developments and the COMET guidelines (an indicator of reliability) $[15,16]$. The most important points characterizing these guidelines are that: their scope is clearly specified, the stakeholder group included both 


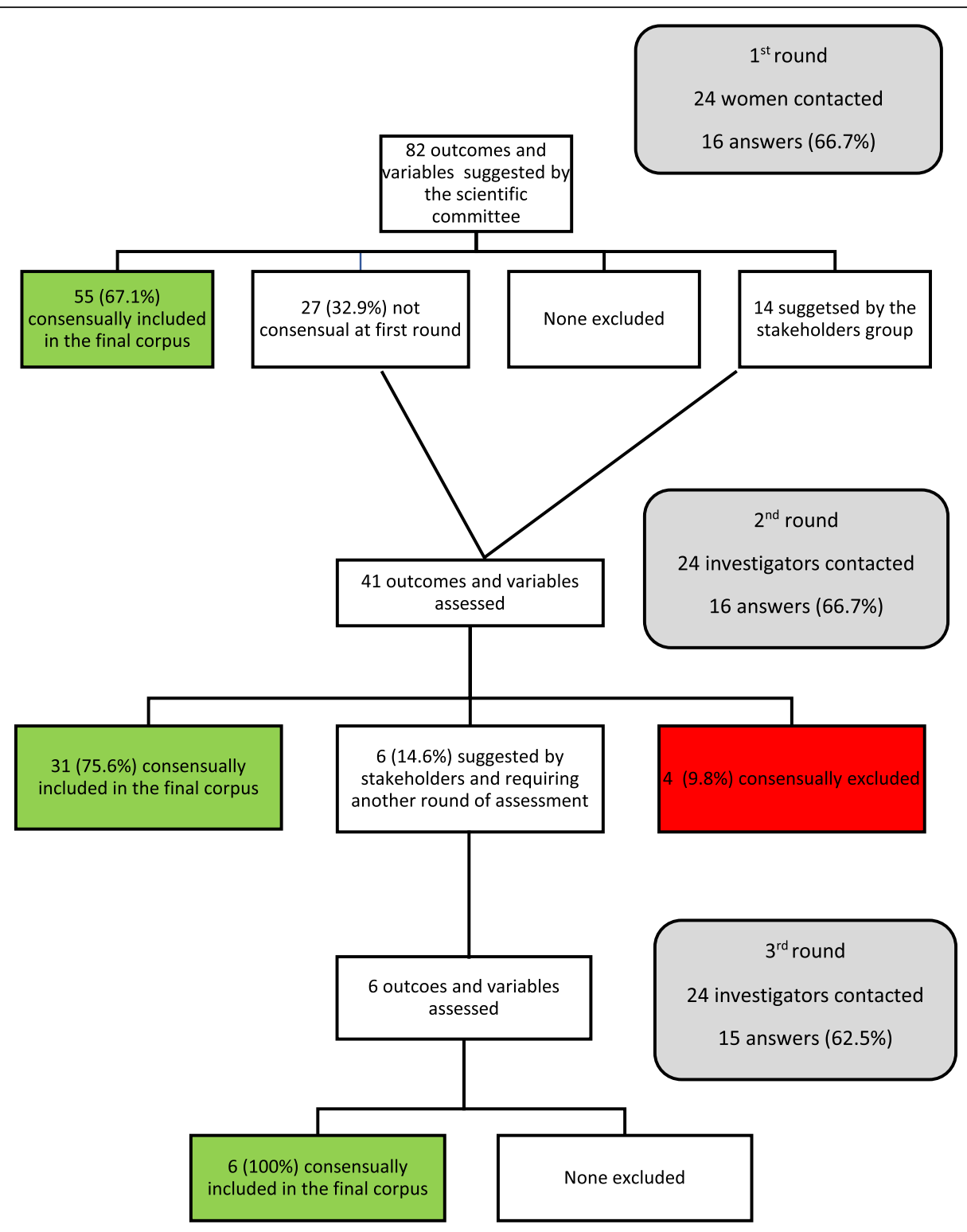

Fig. 2 Flow Chart for the consensus process in the group of women

healthcare professionals and patients, the initial list of suggested outcomes or variables of interest took both healthcare and patient views into consideration, the scoring process and consensus definition were described a priori, as were the criteria for including/dropping items $[15,16]$.

One limitation of our study is the fact that we developed a national core outcome and variable of interest set. This is in accordance with the aim of having it applied in a nationwide French observational study; as regards this objective, in France its interpretation should remain unrestricted. Nevertheless, extrapolation of this core outcome and variable of interest set for potential further study in another country might be limited insofar as it might not deal with medical or societal considerations specific to that country. Manual perineal protection is an excellent example considering that in French maternities all deliveries are performed with a "hands-on approach" and in French obstetrical and midwives' schools, only the hands-on approach is learned. So much said, our core outcome and variable of interest set reports a minimal list of outcomes and variables that should be addressed. Any specific considerations due to specific practices or specific populations may easily be integrated to this list.

Another limitation is that our corpus includes an important number of outcomes and variables. When responding to the survey, the stakeholders were aware 
Table 1 Final core outcome and variable of interest set

\begin{tabular}{|c|c|}
\hline \multicolumn{2}{|c|}{$1^{\text {st }}$ part - Women's history and course of pregnancy ( 13 variables) } \\
\hline History of perineal disease & History of depression \\
\hline History of genital mutilation & Last fetal weight estimation before delivery \\
\hline Mother smoking habits & Fundal height at the onset of labor \\
\hline Women's geographic origin & Perineal massage practicing during pregnancy \\
\hline Gestational or preexisting diabetes & Birth project existing in the obstetrical file \\
\hline Vaginismus before the delivery & Self-rated anxiety before delivery \\
\hline Anal incontinence during pregnancy & \\
\hline \multicolumn{2}{|c|}{$2^{\text {nd }}$ part - Course of labor (14 variables) } \\
\hline Spontaneous or induced labor & Maternal fever $\left(38.5^{\circ} \mathrm{C}\right.$ or higher) during labor \\
\hline Methods for inducing labor & Use of oxytocin \\
\hline Existence of an epidural analgesia & Self-rated perineal pain before pushing \\
\hline Second stage of labor length & Self-rated concern before operative delivery \\
\hline Overall labor length & Self-rated physical fatigue before operative delivery \\
\hline Perineal massage during $2^{\text {nd }}$ stage of labor & Self-rated psychological fatigue before operative delivery \\
\hline $\begin{array}{l}\text { Warm compress application on perineum during } \\
2^{\text {nd }} \text { stage of labor }\end{array}$ & Attempt of manual fetal rotation of fetal head \\
\hline \multicolumn{2}{|c|}{$3^{\text {rd }}$ part - Operative vaginal delivery modalities ( 23 variables) } \\
\hline Indication for operative delivery & Time interval between instrument application and birth \\
\hline Justification for the type of instrument & Timing for instrument removal from fetal head \\
\hline Type of instrument & Analysis of fetal heart rate during pushing phase \\
\hline Shoulder dystocia occurrence & Active delivery of the anterior arm \\
\hline Hour of delivery & Birth position before operative delivery \\
\hline Sequential instrument use & Change of birth position before operative delivery \\
\hline $\begin{array}{l}\text { Orientation of fetal head at the instrument } \\
\text { application }\end{array}$ & Self-rated pain during operative delivery \\
\hline Orientation of the fetal head occiput at crowning & Fundal pressure \\
\hline Obstetrician's skill & Timing for information about operative delivery \\
\hline Fetal head station & Mother's consent for operative delivery \\
\hline Ultrasound assessment of fetal head station & Presence of an accompanying person \\
\hline \multicolumn{2}{|l|}{$\begin{array}{l}\text { Time interval between the onset of pushing and } \\
\text { instrument application }\end{array}$} \\
\hline \multicolumn{2}{|c|}{$4^{\text {th }}$ part - Episiotomy modalities (13 variables) } \\
\hline Type of episiotomy & Obstetrician's skill \\
\hline Indication for episiotomy & Analgesia for episiotomy incision \\
\hline Timing for episiotomy incision & Analgesia for episiotomy reparation \\
\hline Self-declared angle section from midline & Self-rated pain during episiotomy incision \\
\hline Self-declared length of section & Technique used for repairing episiotomy \\
\hline $\begin{array}{l}\text { Timing for women's information about } \\
\text { episiotomy }\end{array}$ & Type of suture thread used \\
\hline $\begin{array}{l}\text { Modality for collecting mother's consent to } \\
\text { episiotomy }\end{array}$ & \\
\hline \multicolumn{2}{|c|}{$5^{\text {th }}$ part - Immediate maternal morbidity (19 outcomes) } \\
\hline Perineal tear occurrence & Perineal hemorrhage of more than $500 \mathrm{~mL}$ \\
\hline Technique used for repairing perineal tears & Blood transfusion requirement \\
\hline $\begin{array}{l}\text { Type of suture thread used for repairing perineal } \\
\text { tear }\end{array}$ & Postpartum urinary retention \\
\hline Perineal hematoma requiring surgical drainage & Psychological care required after childbirth \\
\hline Perineal infection & Difficulty for mother-child relationship \\
\hline Perineal dehiscence & Difficulty for moving \\
\hline Self-rated degree of satisfaction during childbirth & $\begin{array}{l}\text { Self-rated level of understanding about interventions for } \\
\text { the delivery }\end{array}$ \\
\hline Maximal pain felt at the perineum & Mother admission into intensive care unit \\
\hline Self-rated perineal pain 3 days after delivery & Mother death \\
\hline Mother's analgesic consumption & \\
\hline \multicolumn{2}{|c|}{$6^{\text {th }}$ part - One-year maternal morbidity ( 20 outcomes) } \\
\hline Postnatal anal incontinence & Perineal pain other than dyspareunia \\
\hline Postnatal urinary incontinence & Postnatal perineal physical therapy \\
\hline Perineal surgery since childbirth & Any consultation for perineal pain since childbirth \\
\hline $\begin{array}{l}\text { Any consultation for anal incontinence since } \\
\text { childbirth }\end{array}$ & Depression \\
\hline $\begin{array}{l}\text { Any consultation for urinary incontinence since } \\
\text { childbirth }\end{array}$ & Any consultation for depression since childbirth \\
\hline Sexual intercourse since childbirth & Antidepressants consumption since childbirth \\
\hline Postnatal dyspareunia & Existence of another planned pregnancy \\
\hline Sexual function assessment & $\begin{array}{l}\text { In case of another pregnancy, existence of a wish for a } \\
\text { vaginal delivery }\end{array}$ \\
\hline Self-rated satisfaction about sexuality & $\begin{array}{l}\text { In case of another pregnancy, existence of a wish for a } \\
\text { birth project establishment }\end{array}$ \\
\hline Postnatal vaginismus & Self-rated health \\
\hline \multicolumn{2}{|c|}{$7^{\text {th }}$ part - Immediate neonatal morbidity ( 12 outcomes) } \\
\hline Apgar score at five minutes & Skull fracture \\
\hline Arterial cord $\mathrm{pH}$ & Cephalhematoma, subgaleal hemorrhage \\
\hline Birthweight & Analgesic consumption \\
\hline Neonatal cephalic marks & $\begin{array}{l}\text { Neonate admission in a different unit of care than his } \\
\text { mother }\end{array}$ \\
\hline Clavicle fracture & Neonate admission into intensive care \\
\hline Humeral fracture & Neonate death \\
\hline
\end{tabular}


that the INSTRUMODA study will involve 15,000 women within 130 maternities and so will be one of the largest prospective cohort about operative vaginal delivery so far. It was requested to the stakeholders to specifically focus on the assessment of the hypothetic association between mediolateral episiotomy and obstetric anal sphincter injury. Nevertheless, it is likely that both women in the community and professionals have included outcomes and variables of interest that should be addressed in the study to allow future secondary analysis in this cohort (for example for other maternal morbidity associated with operative vaginal delivery). This may explain the high number of outcomes and variables of interest considered.

Finally, the response rate in the group of professionals is approximatively $50 \%$ for the first and the second round. This is usual for online surveys especially when there are several rounds of questionnaires with 40 to $70 \%$ of response rate reported in the literature. This low rate of answer might be related to the absence of obligation to answer to the consensus process to participate in the INSTRUMODA study. It is likely that if a complete fulfillment of the questionnaire had been required for an effective participation into the study, the number of answers would have been higher.

\section{Interpretation}

Reporting both women's and professional's expectations appears essential to this research theme. Indeed, the question of episiotomy during childbirth is a highly debated topic of interest for both women and obstetricians. Some consider that episiotomy reduces the risk of OASI at childbirth, whereas others consider it as a form of sexual mutilation or violence against women [17]. However, that may be, women are asking for better information about this intervention and for greater involvement in the medical decisions related to their giving birth. The British Supreme Court recently held that in order to be able to make autonomous decisions about how to give birth, women have a right to information about any material risk [18]. A consensual approach to definition of the outcome of interest will improve the efficacy of studies on this theme, bringing original data providing women with the information that they are requesting, individualizing this information and thereby so improving our counseling about childbirth.

Some of the variables and outcomes from our corpus might be considered as difficult to assess or address properly, especially for some variables about operative vaginal delivery or episiotomy modalities (timing for instrument removal from the fetal head, self-declared angle section for episiotomy). We anticipated this point considering that in the INSTRUMODA a specific form about the delivery characteristic will be implemented in the recruiting maternities that will contains all the variables of the corpus (for operative vaginal delivery and episiotomy modalities) and it will be requested from the obstetrician to fulfill it immediately after the delivery. With this approach we hope to collect high quality data.

It is interesting to note that most of the suggested outcomes or variables were considered as important by both women and obstetricians, a finding suggesting that the scientific committee's perception of these two population's expectations was close to what they really are. The most important elements brought to light by the core outcome and variable of interest set process were women's imperative need to improve communication and to further investigate psychological aspects: timing and modality of consent for both operative delivery and episiotomy decisions, evaluation of mental attitude and causes for concern, level of understanding etc.... This is in accordance with increasing requests for information and the above-mentioned principle of respect for individual autonomy. This reflection confirms the validity of our results, which are in congruence with the current societal debate about the autonomy of women to make decisions about childbirth.

The few points of discordance between the women's and the obstetrician's process were: women's geographic origin, maternal smoking, episiotomy characteristics (length and angle), number of vaginal examinations, hour of birth. For the first two reported outcomes, this discordance reflects the debate that exists in the literature as to whether these factors should be considered as risk factors of OASI [2-4]. As regards the discordance concerning the collection of episiotomy characteristics, we can hypothesize that these items were more frequently considered by obstetricians because they might be viewed as an evaluation of their practices (whether or not the episiotomies they performed were satisfactory); in some instances, they did not wish to investigate these outcomes. The episiotomy technique is indeed important, given that to be protective a mediolateral episiotomy should be at least at $45^{\circ}$ from the midline after suture, which implies a section at $60^{\circ}$ minimum $[1,2,13]$. This point is more often considered as important by women, insofar as they who probably consider that if they have to undergo an episiotomy, they prefer it to be extended as little as possible. Another hypothesis is that obstetricians may have found it difficult to collect accurate data about the characteristics of episiotomy. Indeed, angle section is self-declared, producing low fidelity information along with the self-declared length. This observation is supported by a French study reporting that a number of episiotomies are not performed as recommended by international guidelines [1, 2, 13, 19]. Both suggestions "self-declared angle section from midline" and "measured angle section from midline" were assessed through 
the consensus process and only "self-declared angle of episiotomy" was considered as important. It is likely that the number of vaginal examinations is more often considered by women as an important outcome because they are the ones concerned with these examinations and the associated discomfort, whereas the obstetrician's intervention is focused on the end of the labor. The hour of birth might be a marker of organizational constraints (in some maternity units, obstetricians are not permanently present during the night) that may affect childbirth management, and this is likely to be more obvious for professionals than for women. With this core outcome and variable of interest set, we expect to provide original data through the INSTRUMODA study, which will be the largest prospective cohort of operative vaginal delivery in nulliparous women. We believe that our results might improve the effectiveness of international guidelines about OASI and operative delivery, which have been disappointing regarding preventive strategies and information to deliver to women.

\section{Conclusion}

We have developed a core outcome and variable of interest set of 114 consensual outcomes for both professionals and women in order to investigate the effect of mediolateral episiotomy on OASI occurrence during operative vaginal delivery in nulliparous women. This core outcome and variable of interest set will be applied in the INSTRUMODA study, which is a prospective nationwide cohort on operative vaginal delivery in nulliparous, for which 15,000 inclusions are expected for 1 year.

\section{Abbreviations}

GROG: French research group in obstetrics and gynecology (Groupe de Recherche en Obstétrique et Gynécologie); OASI: Obstetric Anal Sphincter Injury

\section{Supplementary Information}

The online version contains supplementary material available at https://doi. org/10.1186/s12884-021-03603-0

Additional file 1. Online questionnaire for the obstetricians' stakeholder group.

Additional file 2. Online questionnaire for the women in the community stakeholder group.

\section{Acknowledgements}

The authors acknowledge all women and all professionals who agreed to answer the three rounds of questionnaires to complete this core outcome set procedure.

\section{Authors' contributions}

BG - Study design, data collection, data analysis, main text writing. TS Contribution to study design, data analysis and review of each version of the manuscript. FA - Contribution to study design, data analysis and review of each version of the manuscript. OP - Contribution to study design, data analysis and review of each version of the manuscript. RDT - Contribution to study design, data analysis and review of each version of the manuscript. GD - Contribution to study design, data analysis and review of each version of the manuscript. CLR - Contribution to study design, data analysis and review of each version of the manuscript. ACP - Contribution to study design, data analysis and review of each version of the manuscript. CG - Contribution to study design, data analysis and review of each version of the manuscript. DR - Contribution to study design, data analysis and review of each version of the manuscript. FP - Contribution to study design, data analysis and review of each version of the manuscript. SR - Methodologist, study design. XF Scientific director, study design, data analysis and contribution to main text writing. GROG - National obstetric research network which contributes to the implementation of the study. The author(s) read and approved the final manuscript.

\section{Funding}

This study is supported by a grant from the French Ministry of Health (PHRC: Programme Hospitalier de Recherche Clinique, 2019). The funding body was not involved in the design of the study neither in collection, analysis or interpretation of data.

\section{Availability of data and materials}

The datasets generated and analyzed during the current study are available from the corresponding author on reasonable request.

\section{Declarations}

Ethics approval and consent to participate

This study involves only volunteers for anonymous online questionnaire answering, without any identifying information collection and with a total independence from any medical care. This considered, regarding the French legislation about medical research involving human person (Loi Jardé), an ethical committee approbation is not required (https://www.legifrance.gouv. $\mathrm{fr} /$ codes/id/LEGISCTA000032722874/2017-06-14/).

The INSTRUMODA study was registered on https://clinicaltrials.gov on June 25, 2020 (NCT 04446780). The INSTRUMODA project have been approved by an ethical committee: Comité de Protection des Personnes Nord Ouest IV (ID RCB: 2020-A01974-35).

\section{Consent for publication}

Not applicable.

\section{Competing interests}

The authors declare that they have no competing interests.

\section{Author details}

${ }^{1}$ Poitiers University Hospital, Department of Obstetrics and Gynecology, Poitiers, France. ${ }^{2}$ INSERM CIC-P 1402, Poitiers University Hospital, Poitiers, France. ${ }^{3}$ Nantes University, Movement - Interactions - Performance, MIP, EA4334, Nantes, France. ${ }^{4}$ Robert Debre Hospital, Department of Obstetrics and Gynecology, Paris, France. ${ }^{5}$ Patients representative. CIANE, Collectif inter associatif autour de la naissance, Paris, France. 'Paule de Viguier Maternity, Toulouse University Hospital, Toulouse, France. ${ }^{7}$ Caremeau University Hospital, Department of Obstetrics and Gynecology, Nimes, France. ${ }^{8} \mathrm{Centre}$ Hospitalier Départemental de La Roche sur Yon, Department of Obstetrics and Gynecology, La Roche sur Yon, France. ${ }^{9}$ Port Royal maternity unit, Cochin Hospital, APHP, Paris, France. ${ }^{10}$ Caen University Hospital, Department of Obstetrics and Gynecology, Caen, France. ${ }^{11}$ Jeanne de Flandres maternity unit, Lille University Hospital, Lille, France. ${ }^{12}$ Grenoble University Hospital, Department of Obstetrics and Gynecology, Grenoble, France.

Received: 11 October 2020 Accepted: 29 January 2021

Published online: 25 March 2021

References

1. Royal College of Obstetricians and Gynaecologists. Green-top Guideline No. 29. The management of third- and fourth-degree perineal tears. 2015. Available at: https://www.rcog.org.uk/globalassets/documents/guidelines/ gtg-29.pdf (last consultation on the 22/10/2020).

2. Ducarme G, Pizzoferrato AC, de Tayrac R, Schantz C, Thubert T, le Ray C, Riethmuller D, Verspyck E, Gachon B, Pierre F, Artzner F, Jacquetin B, Fritel X. Perineal prevention and protection in obstetrics: CNGOF clinical practice guidelines. J Gynecol Obstet Hum Reprod. 2019;48(7):455-60. https://doi. org/10.1016/j.jogoh.2018.12.002. 
3. Fritel X, Gachon B, Desseauve D, Thubert T. Anal incontinence and obstetrical anal sphincter injuries, epidemiology and prevention. Gynecol Obstet Fertil Senol. 2018;46(4):419-26. https://doi.org/10.1016/j.gofs.2018.01. 004.

4. Pergialiotis V, Vlachos D, Protopapas A, Pappa K, Vlachos G. Risk factors for severe perineal lacerations during childbirth. Int J Gynaecol Obstet. 2014; 125(1):6-14. https://doi.org/10.1016/j.jigo.2013.09.034.

5. Gachon B, Fradet Menard C, Pierre F, Fritel X. Does the implementation of a restrictive episiotomy policy for operative deliveries increase the risk of obstetric anal sphincter injury? Arch Gynecol Obstet. 2019;300(1):87-94. https://doi.org/10.1007/s00404-019-05174-0.

6. De Leeuw JW, de Wit C, Kuijken JP, et al. Mediolateral episiotomy reduces the risk for anal sphincter injury during operative vaginal delivery. BJOG. 2008;115(1):104-8. https://doi.org/10.1111/j.1471-0528.2007.01554.x.

7. Sultan $\mathrm{AH}$, Thakar R, Ismail KM, Kalis V, Laine K, Räisänen SH, de Leeuw JW. The role of mediolateral episiotomy during operative vaginal delivery. Eur J Obstet Gynecol Reprod Biol. 2019;240:192-6. https://doi.org/10.1016/j. ejogrb.2019.07.005

8. Van Bavel J, Hukkelhoven C, de Vries C, et al. The effectiveness of mediolateral episiotomy in preventing obstetric anal sphincter injuries during operative vaginal delivery: a ten-year analysis of a national registry. Int Urogynecol J. 2018;29(3):407-13. https://doi.org/10.1007/s00192-01 7-3422-4.

9. Jiang H, Qian X, Carroli G, Garner P, Cochrane Pregnancy and Childbirth Group. Selective versus routine use of episiotomy for vaginal birth. Cochrane Database Syst Rev. 2017;2:CD000081. https://doi.org/10.1002/14 651858.CD000081.pub3.

10. De Vogel J, van der Leeuw-van Beek A, Gietelink D, et al. The effect of a mediolateral episiotomy during operative vaginal delivery on the risk of developing obstetrical anal sphincter injuries. Am J Obstet Gynecol. 2012; 206:404e401-5.

11. Murphy DJ, Macleod M, Bahl R, Goyder K, Howarth L, Strachan B. A randomised controlled trial of routine versus restrictive use of episiotomy at operative vaginal delivery: a multicentre pilot study. BJOG. 2008;115(13): 1695-702. https://doi.org/10.1111/j.1471-0528.2008.01960.x.

12. Royal College of Obstetricians and Gynaecologists. Green-top guideline no. 26: operative vaginal delivery. 2020. Available at: https://obgyn.onlinelibrary. wiley.com/doi/pdf/10.1111/1471-0528.16092 (last consultation on the 22/10/ 2020).

13. World Health Organization. Intrapartum care for a positive childbirth experience. 2019. Available at: https://www.who.int/publications/i/item/ 9789241550215 (last consultation on the 22/10/2020).

14. Hughes KL, Kirkham JJ, Clarke M, Williamson PR. Assessing the impact of a research funder's recommendation to consider core outcome sets. PLoS One. 2019;14(9):e0222418. https://doi.org/10.1371/journal.pone.0222418.

15. Kirkham JJ, Gorst S, Altman DG, Blazeby JM, Clarke M, Devane D, Gargon E, Moher D, Schmitt J, Tugwell P, Tunis S, Williamson PR. Core Outcome SetSTAndards for Reporting: The COS-STAR Statement. PLoS Med. 2016;13(10): e1002148. https://doi.org/10.1371/journal.pmed.1002148.

16. Williamson PR, Altman DG, Bagley H, Barnes KL, Blazeby JM, Brookes ST, Clarke M, Gargon E, Gorst S, Harman N, Kirkham JJ, McNair A, Prinsen CAC, Schmitt J, Terwee CB, Young B. The COMET handbook: version 1.0. Trials. 2017;18(S3):280. https://doi.org/10.1186/s13063-017-1978-4.

17. Haut conseil à l'égalité entre les femmes et les hommes. Les actes sexistes durant le suivi gynécologique et obstétrical. 2018. Available at: http://www. haut-conseil-egalite.gouv.fr/IMG/pdf/hce_les_actes_sexistes_durant_le_ suivi_gynecologique_et_obstetrical_20180629.pdf (last consultation on the 22/10/2020)

18. Bolton $\mathrm{H}$. The Montgomery ruling extends patient autonomy. BJOG. 2015; 122(9):1273. https://doi.org/10.1111/1471-0528.13467.

19. Bechard F, Geronimi J, Vieille P, et al. Are we performing episiotomies correctly? A study to evaluate French technique in a high-risk maternity unit. J Gynecol Obstet Hum Reprod. 2018;47(7):331-8. https://doi.org/10.101 6/j.jogoh.2018.04.010.

\section{Publisher's Note}

Springer Nature remains neutral with regard to jurisdictional claims in published maps and institutional affiliations.

Ready to submit your research? Choose BMC and benefit from:

- fast, convenient online submission

- thorough peer review by experienced researchers in your field

- rapid publication on acceptance

- support for research data, including large and complex data types

- gold Open Access which fosters wider collaboration and increased citations

- maximum visibility for your research: over $100 \mathrm{M}$ website views per year

At BMC, research is always in progress.

Learn more biomedcentral.com/submissions 